\title{
A thermodynamic assessment of working fluids in ORC systems
}

\author{
Dominika Matuszewska ${ }^{1, *}$, Marta $\mathrm{Kuta}^{1}$, and Jan Górski ${ }^{1}$ \\ ${ }^{1}$ AGH University of Science and Technology, Faculty of Energy and Fuels, Department of Thermal and Fluid Flow Machines, \\ al. A. Mickiewicza 30, 30-059 Krakow
}

\begin{abstract}
ORC (Organic Rankine Cycle) is widely used to convert low temperature heat into electricity using organic working fluid. The performance of an ORC installation is influenced deeply by selected working fluid and operation conditions. Recently has been presented a new generation of working fluids dedicated to ORC systems. They are characterized by near zero ODP (Ozone Depletion Potential) coefficient and significantly smaller GWP (Global Warming Potential) in comparison with currently used refrigerants. This paper presents preliminary research on selected dry and isentropic ORC fluids and some peculiarities in their behaviour.
\end{abstract}

\section{Introduction}

The demand for electric and mechanical energy has been growing form year to year since the invention of the first one. On the one hand, increased awareness of the problems associated with the use of fossil fossil means that society is becoming more aware of the negative impact of energy on the environment (such as pollution and global warming potential, ozone layer depletion and acid rain) and is looking a new solutions. In this light, it can be observed an increased interest in sustainable development, utilization of low-temperature and waste heat sources, environmental protection or using renewable energy technologies.

Commonly used Rankine cycle, with water as working fluid, is not always suitable for low and medium temperature energy resources due to the boiling temperature of water which may be too high for this. In additions, using steam cycle causes a number of other problems such as the need of superheating (to prevent condensation of water during expansion), increased risk of turbine blades erosion or complicated construction of the turbine and its relatively high price [1].

Many other cycles, for the conversion of low temperature heat, have been proposed and analyzed, among them can be find solutions such as: organic Rankine cycle (ORC), supercritical Rankine cycle, Kalina cycle or flash cycle. However, organic Rankine cycle seems to be the most suitable one due to its simple design, easy maintenance and high reliability. Organic Rankine cycle has similar construction to steam Rankine cycle but because of the use of organic working fluids with lower boiling point than water, it can utilize various types of heat sources. ORC is widely used with such sources as: industrial waste heat [2], solar energy [3], geothermal energy [4,5], biomass energy [6] or ocean energy [7], etc. In order to improved the cycle efficiency various combinations of ORC cycles are studied, including fuel cells [8], internal combustion engines [9], gas turbines [10] or thermoelectric generators [11], etc. The performance of an organic Rankine cycle is influenced deeply by selected working fluid - type of working medium and thermal physical properties. However, some problems can occur during selection of working fluid into ORC cycle, such as incomplete date on its thermal, transport or environment properties.

During evaluation also some other fact should be taken under consideration, including the material compatibility, flammability and toxicity, hazardous influence on environment, which can limit usefulness of given working fluid [12].

\section{Working fluid selection}

The selection of working fluid for ORC installation is crucial matter in this type of application. The choice of working fluid affects not only the system efficiency but also the installation components size and the expansion machine design. The selection of working fluid for ORC system is more complicated than for other one, including Kalina cycle - where composition of working fluids is set (but there can be come mass fraction variations) or compression refrigeration cycle - where working conditions are fixed. The complexity of working fluid selection for ORC systems is associated with such matters as [12-14]:

- The condition of work and type of heat source for ORC can vary widely - from low$\left(\sim 80^{\circ} \mathrm{C}\right)$ to high-temperature $\left(\sim 500^{\circ} \mathrm{C}\right)$ heat sources, such as low-temperature geothermal or solar source or high-temperature biomass or exhausted gases from gas turbine 
- Very large number of substance that can be used as working fluid candidate for ORC system, such as hydrocarbons (including also the aromatic one), ethers, perflurocarbons, hydrofluoroolefines, siloxans or alcohols.

\subsection{The saturation vapour curve}

Working fluids can be divided into categories based on the saturation vapour line, which is one of the most important working fluid characteristic in ORC systems. The tape of saturation vapour line influence not only on system efficiency but also the design of system and the equipment need for working. The figure 1 shows that generally there is three types of working fluids based on the saturation vapour line: a dry fluid with positive slope (water, ammonia), a wet fluid with negative slope and with nearly vertical vapour saturation curve - an isentropic fluid (R11). In case of the isentropic fluid, the saturated vapour at the inlet of turbine expands along vertical line and remain saturated leaving the turbine with no condensation. Other additional benefit of using this type of fluids (next to expansion along vertical line) is that this type of fluids do not need regenerator to be installed. Those two factors cause that the isentropic fluids are the best option for ORC cycles. In case of using dry fluid in ORC, the saturated vapour of dry fluid at the inlet of turbine becomes superheated after isentropic expansion. Both dry and isentropic fluids do not need superheating during cycle that eliminate concerns about corrosion of turbine blades. For those reasons, dry and isentropic type of fluids are the best solution for ORC cycle.

Concluding the main characteristic of working fluids adequate for ORC system: mostly they are organic fluids, with high molecular weight, much lower pressure and temperature than water and due to the shape of slope the do not need superheating. This factors results that those working fluids can utilize even low-temperature heat source. However, there are still some problems with ORC working fluids connected with the material compatibility, security for human health and environment. Until recently, the most widely use fluids had been hydrocarbons (HC's) and its derivatives (HFC, HCFC) due to their low boiling point but nowadays the use of some of theme is taken under limitation because of their negative impact on environment (high ODP, GWP). There are still conducted work to develop the new, environmental friendly groups. Recent work emerge a new group of working fluids especially dedicated to ORC systems - hydrfluoroolefins (HFO's), siloxany, etc [12]. In this paper, some selected fluids have been presented in Table 1 with their main properties. All fluids are arranged on the basis of their chemical classes.

Based on the data presented in Table 1, intuitively the working fluid can be divided in two groups. The first one contains mostly all hydrocarbons and their derivatives with low-boiling point (NBP) close to the ambient temperature. While, the second group contains two hydrocarbons (n-dodecane and toluene) and siloxanes with high-boiling point. For all mentioned working fluids, the retrograde and other phenomena can occur in low stability region in the dense vapours, which can be connect with thermodynamic stability parameters [15].
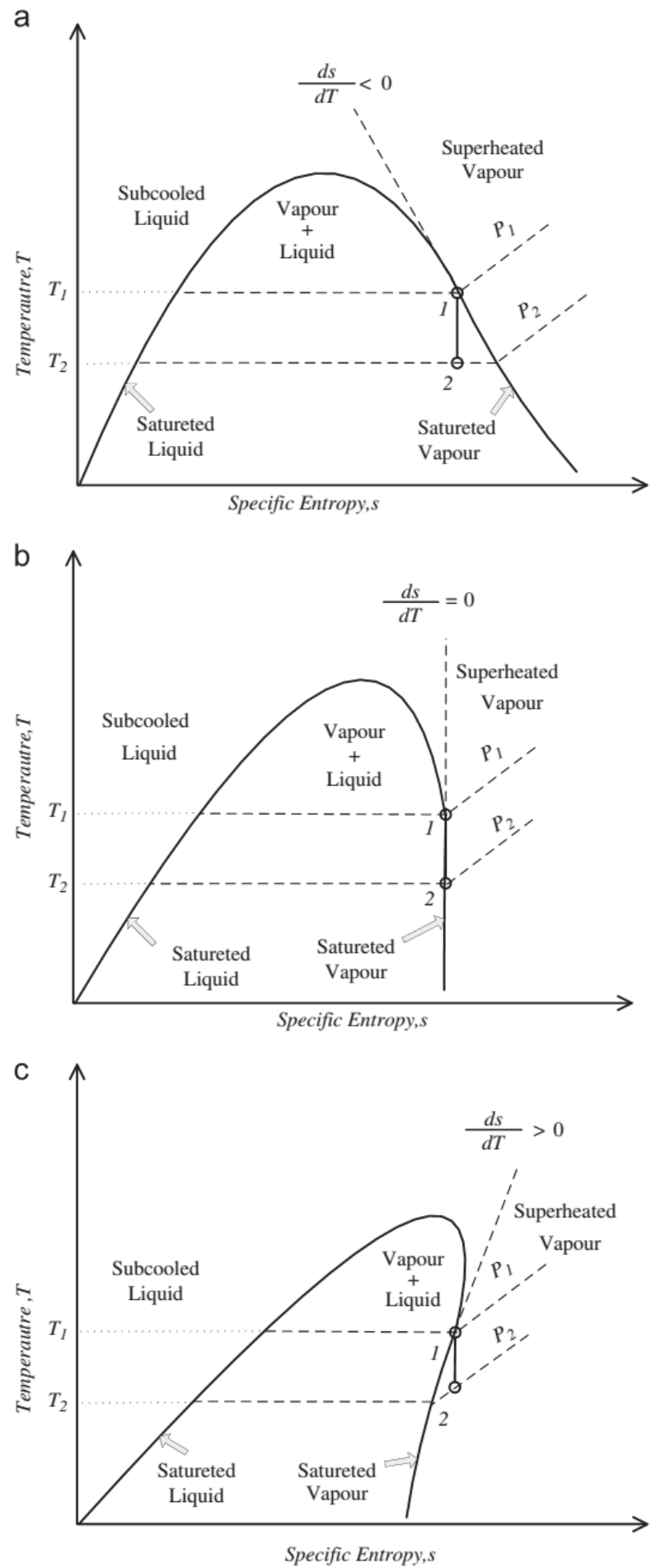

Fig. 1. Diagram T-s for fluids (a) wet, (b) isentropic and (c) dry [14]

On the basis of the data collected in Table 1, it can be notice that the value of acentric factor $\omega$ rise with growth of molecular mass of working fluid. 
Table 2. Pure working fluid candidates for ORC

\begin{tabular}{|c|c|c|c|c|c|}
\hline \multirow{2}{*}{ Fluid } & \multirow{2}{*}{$\begin{array}{c}\text { Molar } \\
\text { mass } \\
\mathrm{M} \\
\mathrm{g} / \mathrm{mol}\end{array}$} & \multicolumn{2}{|c|}{ Critical point } & \multirow{2}{*}{$\begin{array}{c}\mathrm{NBP} \\
\mathrm{K}\end{array}$} & \multirow{2}{*}{$\begin{array}{l}\text { Acentric } \\
\text { Factor } \omega\end{array}$} \\
\hline & & $\begin{array}{l}\mathrm{P}_{\mathrm{c}} \\
\text { bar }\end{array}$ & $\begin{array}{l}\mathrm{T}_{\mathrm{c}} \\
\mathrm{K}\end{array}$ & & \\
\hline \multicolumn{6}{|c|}{ Hydrocarbons (HCs) } \\
\hline N-butane & 58.12 & 37.9 & 425.1 & $\begin{array}{c}273 . \\
0\end{array}$ & 0.201 \\
\hline N-dodecane & 170.0 & 29.3 & 374.9 & $\begin{array}{c}256 . \\
8\end{array}$ & 0.357 \\
\hline Toluene & 92.14 & 41.3 & 591.8 & $\begin{array}{c}383 . \\
8\end{array}$ & 0.266 \\
\hline \multicolumn{6}{|c|}{ Hydrofluorocarbons (HFCs) } \\
\hline $\mathrm{R} 134 \mathrm{a}$ & 102.0 & 40.6 & 374.2 & $\begin{array}{c}247 . \\
1\end{array}$ & 0.327 \\
\hline R227ea & 170.0 & 29.3 & 374.9 & $\begin{array}{c}256 . \\
8\end{array}$ & 0.357 \\
\hline $\mathrm{R} 245 \mathrm{fa}$ & 134.1 & 36.5 & 427.2 & $\begin{array}{c}288 . \\
3\end{array}$ & 0.378 \\
\hline \multicolumn{6}{|c|}{ Hydrofluoroolefins (HFOs) } \\
\hline R1234yf & 114.0 & 33.8 & 367.9 & $\begin{array}{c}243 . \\
7\end{array}$ & 0.276 \\
\hline R1234zeE & 114.0 & 36.4 & 382.5 & $\begin{array}{c}254 . \\
2\end{array}$ & 0.313 \\
\hline R1234zeZ & 114.0 & 35.3 & 423.3 & $\begin{array}{c}282 . \\
9\end{array}$ & 0.327 \\
\hline \multicolumn{6}{|c|}{ Hydrochlorofluorocarbons (HCFCs) } \\
\hline R123 & 152.9 & 36.6 & 456.8 & $\begin{array}{c}301 . \\
0\end{array}$ & 0.282 \\
\hline \multicolumn{6}{|l|}{ Siloxanes } \\
\hline $\mathrm{MM}$ & 162.4 & 19.4 & 518.8 & $\begin{array}{c}373 . \\
4\end{array}$ & 0.418 \\
\hline MDM & 263.5 & 14,2 & 564.1 & $\begin{array}{c}425 . \\
7\end{array}$ & 0.529 \\
\hline MD2M & 310.7 & 12.3 & 599.4 & $\begin{array}{c}467 . \\
5\end{array}$ & 0.668 \\
\hline MD4M & 459.0 & 8.8 & 653.2 & $\begin{array}{c}533 . \\
9\end{array}$ & 0.825 \\
\hline D4 & 296.6 & 13.3 & 586.5 & $\begin{array}{c}448 . \\
5\end{array}$ & 0.592 \\
\hline D5 & 370.8 & 11.6 & 619.2 & $\begin{array}{c}484 . \\
1\end{array}$ & 0.658 \\
\hline D6 & 444.9 & 9.6 & 645.8 & $\begin{array}{c}518 . \\
1\end{array}$ & 0.736 \\
\hline
\end{tabular}

\subsection{ORC fluids behaviour on saturation line}

The phenomena of dense gas flow are not know enough nowadays. The composed molecular structure of heavy fluids cause very often non-classical behaviour near the saturated vapour line $(\mathrm{x}=1)$. However, it is very important to analyze and study the measures of fluid complexity and associate theme with some parameters or particular fluid behaviour.

The molecular complexity can give information about the shape of slope of saturated vapour line and thereby whether fluid is dry, isentropic or wet. Parameter $\sigma$ is usually referred to the reduced temperature $T_{r}=0.7$ and defined as [14-16]

$$
\begin{gathered}
\sigma_{T r=0.7}=\frac{T_{c}}{R}\left(\frac{d s}{d T}\right)_{x=1}= \\
=\frac{T_{c}}{R}\left[\left(\frac{\partial s}{\partial p}\right)_{T}\left(\frac{d p}{d T}\right)_{x=1}+\left(\frac{\partial s}{\partial T}\right)_{p}\right]_{T r=0.7}
\end{gathered}
$$

The simplified form of eq. (1) :

$$
\sigma_{T r=0.7}=\frac{T_{c}}{R}\left[\frac{c_{p}^{0}}{T}-\frac{R}{p}\left(\frac{d p}{d T}\right)_{x=1}\right]_{T r=0.7}
$$

The $\sigma$ coefficient is primarily a function of the heat capacity of the vapour and as a consequence is directly related to the molecular structure of the fluid. The increment of molecular complexity cause decrement of the heat capacity ratio $\gamma$, tending to one and slope of the saturation vapour line becomes positive. The more positive the more complex is the molecular structure (Figure 2).

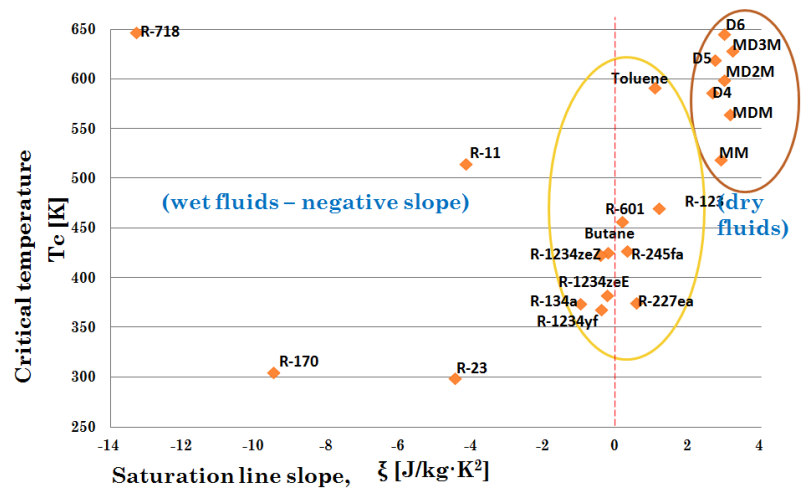

Fig. 2. Wet, isentropic and dry fluids

Using the 'retrogradicity' parameter proposed by Lambrakis, counterpart formulation can be presented [18]:

$$
\tilde{r}_{\sigma}=\left(\frac{\partial T}{\partial v}\right)_{p}\left(\frac{d s}{d p}\right)_{x=1} \geq 0
$$

This parameter is useful during analysis of a supercritical and high-pressure subcritical ORC cycle and shows departure from normal fluids. In this case, the process in the expander is taken in real-gas area all physical constants deeply varies with temperature and pressure. It can be written in form:

$$
\tilde{r}_{\sigma}=\left(\frac{c_{p}^{\prime \prime} T}{\Delta h_{l v}}\right)\left(\frac{z_{v T}}{z_{T v}}\right)^{\prime \prime}\left(1-\frac{v \prime}{v^{\prime \prime}}\right)-1 \geq 0
$$

where parameters $z_{T v}$ and $z_{v T}$ are two Virial Compressibility Derivatives (VCD) functions [15,19]. VCD's can be obtained from Maxwell thermodynamic relations and the Legendre transformation:

$$
z_{T v}=z+T\left(\frac{\partial z}{\partial T}\right)_{v}=z+T_{r}\left(\frac{\partial z}{\partial T_{r}}\right)_{v r}
$$




$$
z_{v T}=z-v\left(\frac{\partial z}{\partial v}\right)_{T}=z-v_{r}\left(\frac{\partial z}{\partial v_{r}}\right)_{T r}
$$

where $z=p v /(R T)$ is the compressibility factor. With some manipulation, this functions can be express as the ratio of partial derivatives :

$$
\begin{aligned}
& z_{T v} \equiv\left(\frac{\partial p}{\partial T}\right)_{v} /\left(\frac{\partial p^{i d}}{\partial T}\right)_{v} \\
& z_{v T} \equiv\left(\frac{\partial p}{\partial v}\right)_{T} /\left(\frac{\partial p^{i d}}{\partial v}\right)_{T}
\end{aligned}
$$

where $p^{\text {id }}=p(T, v)=R T / v$, corresponds to an ideal gas model, where the value of compressibility factor $z$ and the VCD's are equal to one.

The first term in the eq. (4) is the reciprocal of Jacob's Number $J a$ and is always greater than one, while ratio $z_{v T} / z_{T v}$, is less than one.

In some cases the multiplication of these two can gives value close to unity. However, the retrogradicity parameter can be less than zero due to the specific volume ratio $v^{\prime} / v^{\prime \prime}$ that in the sub-critical are for pressure can be neglected. Figure 3 presents the change of Lambrakis parameter for some selected working fluids.

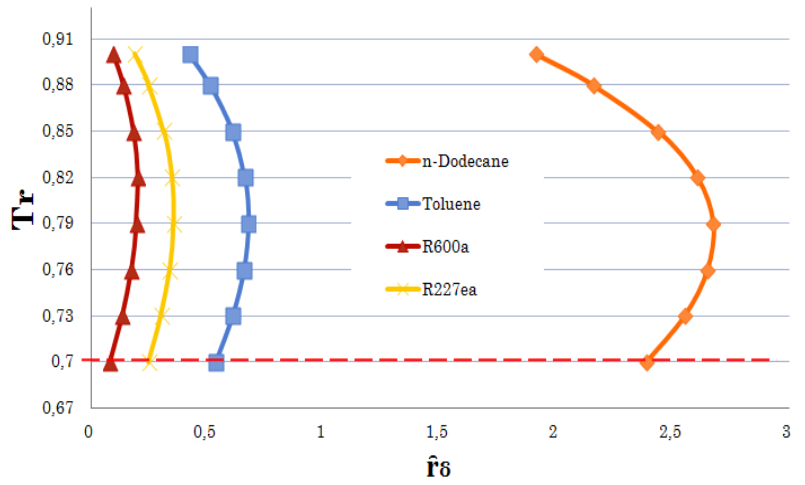

Fig. 3. Lambrakis' parameter for different working fluids

The stability conditions have a significant influence on fluid behaviour in the dense gas region (close the critical point and saturation line) so it seems important to considered if fluid properties respond to that. The thermodynamic stability condition (for one-component homogeneous $p v T$ system) is presented below [19]

$$
D=\frac{\partial(T,-p)}{\partial(s, v)}=\left|\begin{array}{ll}
(\partial T / \partial s)_{v} & (\partial T / \partial v)_{s} \\
(\partial T / \partial v)_{s} & (\partial p / \partial v)_{s}
\end{array}\right| \geq 0
$$

With some manipulations, it can be written:

$$
D=-\left(\frac{\partial p}{\partial v}\right)_{S}\left(\frac{\partial T}{\partial s}\right)_{p}=-\frac{T}{c_{v}}\left(\frac{\partial p}{\partial v}\right)_{T}
$$

Reduced form can be presented by [10]

$$
\bar{D}=D\left(\frac{v_{c}}{T_{c}}\right)^{2}=\frac{R}{c_{v}} Z_{v T}\left(\frac{T_{r}}{v_{r}}\right)^{2}
$$

This equation can use to the stability criterion analysis for the ORC fluids in their dense vapor on the saturation line. The examination of that has been shown in Figures 3-5.

The observation shows a some peculiarities in behavior of selected dry and isentropic fluids. Also, in the high pressure region of slightly superheated vapor, a low stability of dense gas can noticed. The Figure 3 shows the reduced stability $\bar{D}$ of $245 \mathrm{fa}$ dense vapor in region with the temperature range $438<\mathrm{T}_{\mathrm{r}}<445 \mathrm{~K}$ and pressure $0.85<\mathrm{p}_{\mathrm{r}}<1.3$. Around the saturated vapor state, the local minima and the saddle points of isoclines of constant $\bar{D}$ can be revealed.

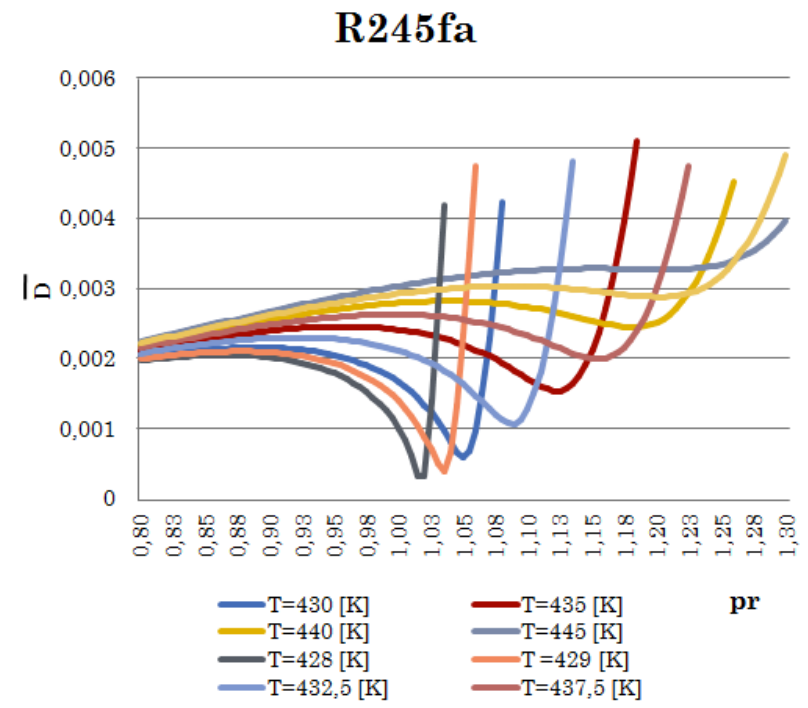

Fig. 3. Reduce thermodynamic stability D of R245fa

For each working fluids, the range of temperature and pressure for reduced stability $\bar{D}$ varies. The Figure 3 shows this variety using as example - R123. The reduce stability $\bar{D}$ for this working fluid dense vapour varies in range of temperature $457<\mathrm{T}_{\mathrm{r}}<470 \mathrm{~K}$, while pressure $0.8<\mathrm{p}_{\mathrm{r}}<1.23$.

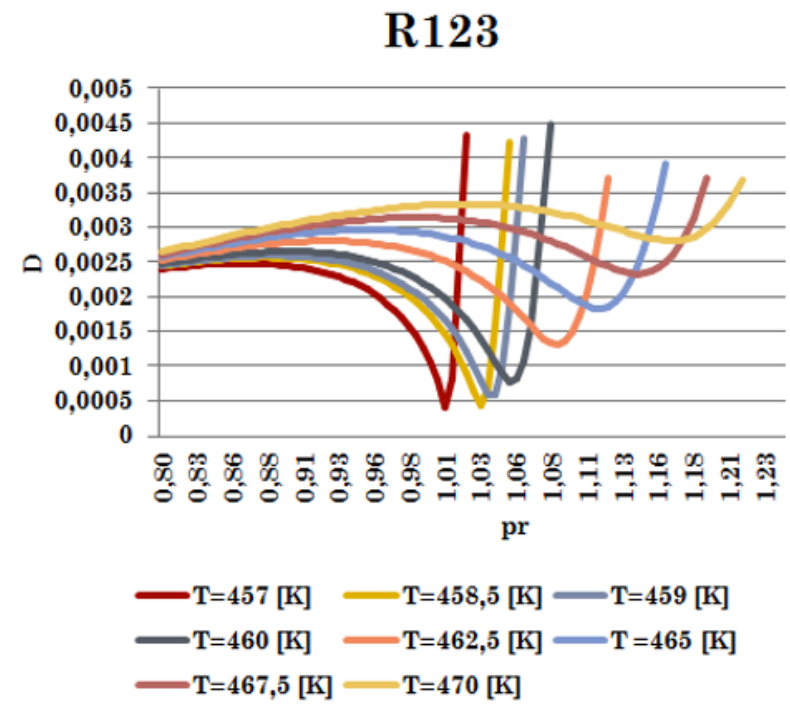

Fig. 4. Reduce thermodynamic stability D of R123

Figure 5 shows relation between reduced thermodynamic stability criterion $\bar{D}$ on the saturated vapour line $(\mathrm{x}=1)$ for all selected working fluids. The working fluids have 
been arrange on the basis of the acentric factor $\omega$. Calculation This ranking has been made for three important point on the saturated vapour line, including temperatures corresponded to $\mathrm{h} "=\max$ and $\mathrm{s} "=\max$ and the reduced temperature $\operatorname{Tr}=0.7$.

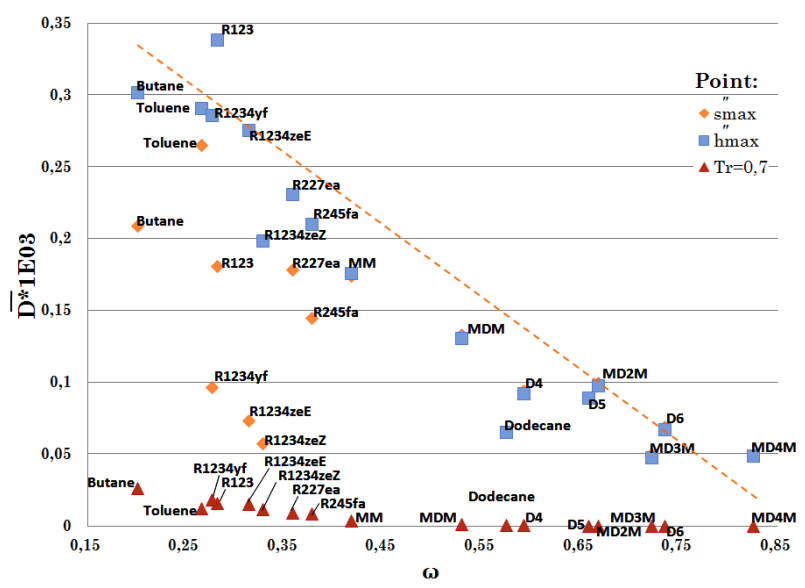

Fig. 5. Stability criterion $\bar{D}$ vs acentric factor $\omega$ for ORC fluids

Based on the Figure 5 can be made certain observation. For high molecular mass and complex fluids such as siloxanes, the stability criterion $\bar{D}$ on the saturation line for reduced temperature $\mathrm{T}_{\mathrm{r}}=0.7$ have achieved values close to zero. For hydrocarbons and its derivatives, the stability criterion (for reduced temperature $\mathrm{T}_{\mathrm{r}}=0.7$ ) is minimally higher and positive (from range $\bar{D}=0.14 \div 0,23 \cdot 10^{-3}$ ). For temperature corresponding to h" ${ }_{\max }$ the stability criterion $\bar{D}$ shows almost linear dependence to the Pitzer's criterion $\omega$. In case of data for $\mathrm{s}^{\prime \prime}{ }_{\max }$ there is hard to observe any regularity to the $\omega$ factor. In case of siloxanes, the stability criterion $\bar{D}$ is almost the same for both $h{ }_{\text {max }}$ and $s{ }^{\prime}$ max $_{\text {ax }}$ conditions on the saturated vapor line. For all analyzed working fluids, the stability criterion $\bar{D}$ for temperatures corresponding to $\mathrm{h}^{\prime}{ }_{\text {max }}$ is higher that to those with s" ${ }_{\text {max. }}$

The data presented it this paper confirms that some peculiarities appear in high-density vapours of ORC fluids corresponding to the thermodynamic parameters and compressible flow conditions.

\section{Conclusions}

The assessment of working fluids in ORC cycles power plant and application is hard and complex, in case of thermodynamic it isn't understand good enough due to the lack of data and still need some additional research. The main conclusions shown that the best working fluids for ORC cycles are isentropic and dry ones. The working fluid for ORC application should be selected individually, depending on temperature of heat source, environmental factors and fluid thermodynamic properties. It is important to remember that all analyzed fluids have high-molecular complexity, which cause that their behaviour is still not well known. The use of complete real properties of ORC fluids can help to improve the performances and efficiency of this cycle.
This work was supported by AGH - University of Science and Technology (Project 11.11.210.376).

\section{References}

1. BF. Tchanche, G. Lambrinos, A. Frangoudakis, G. Papadakis, Renewable and Suitable Energy Reviews 15, 3963-3979 (2011)

2. TC. Hung, TY. Shai, SK. Wang, Energy 22(7), 661667 (1997)

3. R. Rayegan, YX. Tao, Renewable Energy 36(2), 659-670 (2011)

4. T. Guo, HX. Wang, SJ. Zhang, Energy 36(5), 26392649 (2011)

5. Z. Shengjun, W. Huaixin, G. Tao, Applied Energy 88(8), 2740-2754 (2011)

6. H. Liu, Y. Shao, J. Li, Biomass and Bioeenrgy 35(9), 3985-3994 (2011)

7. F. Sun, Y. Ikegami, B. Jia, H. Arima, Applied Ocenad Research 35, 38-46 (2012)

8. P. Zhao, J. Wang, I. Gao, Y. Dai, Internationa Journal of Hydrogen Energy 37(4), 3382-3391 (2012)

9. M. He, X. Zhang, K. Zeng, K. Gao, Energy 36(12), 6821-6829 (2011)

10. RF. Garcia, Applied Thermal Engineering 42, 25-33 (2012)

11. G. Shu, J. Zhao, H. Tian, X. Liang, H. Wei, Energy 45, 806-816 (2011)

12. B. Saadatfar, R. Fakhrai, T. Franson, JMES 1, 161 (2012)

13. A. Schuster, S. Karellas, E. Kakaras, Spliethoff H., Epplied Thermal Engineering 29(8-9), 1809-1817 (2009)

14. J. Bao, L. Zhao, Renewable and Sustainable Energy Reviews 24, 325-342 (2013)

15. D. Matuszewska, K. Sztekler, J. Górsi, MATEC Web of Conferfeces 18, 03005 (2014)

16. C. Invernizzi, Energy 11 (2013)

17. P.A. Thompson: Compressible Fluid Dynamics (McGraw Hill, NY, 1988)

18. P. Colonna, A. Guardone, N.R. Nanna, Phys. Fluids 19, 086102 (2007)

19. J. Gorski; Modeling of real gas properties and its thermal-flow processes (in Polish), Oficyna Wyd. 